\title{
Understanding the implementation of maternity waiting homes in low- and middle-income countries: a qualitative thematic synthesis
}

Loveday Penn-Kekana ${ }^{1,2}$, Shreya Pereira ${ }^{3}$, Julia Hussein ${ }^{4 *}$, Hannah Bontogon $^{5}$, Matthew Chersich ${ }^{6}$, Stephen Munjanja ${ }^{7}$ and Anayda Portela ${ }^{5}$

\begin{abstract}
Background: Maternity waiting homes (MWHs) are accommodations located near a health facility where women can stay towards the end of pregnancy and/or after birth to enable timely access to essential childbirth care or care for complications. Although MWHs have been implemented for over four decades, different operational models exist. This secondary thematic +analysis explores factors related to their implementation.

Methods: A qualitative thematic analysis was conducted using 29 studies across 17 countries. The papers were identified through an existing Cochrane review and a mapping of the maternal health literature. The Supporting the Use of Research Evidence framework (SURE) guided the thematic analysis to explore the perceptions of various stakeholders and barriers and facilitators for implementation. The influence of contextual factors, the design of the $\mathrm{MWHs}$, and the conditions under which they operated were examined.

Results: Key problems of MWH implementation included challenges in MWH maintenance and utilization by pregnant women. Poor utilization was due to lack of knowledge and acceptance of the MWH among women and communities, long distances to reach the $\mathrm{MWH}$, and culturally inappropriate care. Poor MWH structures were identified by almost all studies as a major barrier, and included poor toilets and kitchens, and a lack of space for family and companions. Facilitators included reduced or removal of costs associated with using a MWH, community involvement in the design and upkeep of the MWHs, activities to raise awareness and acceptance among family and community members, and integrating culturally-appropriate practices into the provision of maternal and newborn care at the MWHs and the health facilities to which they are linked.

Conclusion: MWHs should not be designed as an isolated intervention but using a health systems perspective, taking account of women and community perspectives, the quality of the $\mathrm{MWH}$ structure and the care provided at the health facility. Careful tailoring of the MWH to women's accommodation, social and dietary needs; low direct and indirect costs; and a functioning health system are key considerations when implementing MWH. Improved and harmonized documentation of implementation experiences would provide a better understanding of the factors that impact on successful implementation.
\end{abstract}

Keywords: Maternity waiting homes, Shelters, Obstetric complications, Childbirth, Referral system, Low and middleincome countries

\footnotetext{
* Correspondence: j.hussein@abdn.ac.uk

${ }^{4}$ Immpact, Institute of Applied Health Sciences, University of Aberdeen,

Foresterhill, Aberdeen AB25 2ZD, Scotland

Full list of author information is available at the end of the article
} 


\section{Background}

Ensuring births with a skilled attendant and births in health facilities has been the key focus of attempts to reduce maternal mortality in the last two decades $[1,2]$. Many women in developing countries live far away or across difficult terrain from facilities. Transport is not always available, or may be difficult or too slow, particularly for women in labour, or when complications have developed [2]. Strategies typically designed for inaccessible areas aim to facilitate the timely movement of women from home to health facility by diminishing barriers that inhibit access to care such as distance, geography, seasonal barriers or the time of day. The interventions relate to improving infrastructure or transport, addressing the cost of transport or enabling communication between referral points [3]. One intervention designed to address accessibility are maternity waiting homes (MWHs). Maternity waiting homes are defined as lodgings or accommodation close to a health facility where women can stay before and sometimes after they give birth. Women staying in MWHs are then able to easily access services for essential childbirth care or obstetric or newborn complications at the nearby facility [4].

MWHs have been advocated for and implemented for over four decades [5]. Current maternal health strategies embrace MWHs, including the Campaign on Accelerated Reduction of Maternal, Newborn \& Child Mortality in Africa (CARMMA) programme in South Africa [6], Saving Mothers Giving Lives in Zambia and Uganda [7], Gates funded projects in Malawi [8] and the Plan of Action to Accelerate the Reduction of Maternal Morality and Severe Maternal Morbidity for the Americas [9]. Different operational models of MWHs exist. In the past, MWH programmes targeted women most at risk of developing obstetric complications [10-14]. More recently, the focus has expanded to all pregnant women who would otherwise have problems accessing facilities for birth [3, 10, 15-17].

In 2015 the World Health Organization (WHO) published Recommendations on Health Promotion Interventions for Maternal and Newborn Health [4]. An intervention assessed within this guideline include MWHs. The Guideline Development Group reviewed the evidence collected and concluded that "MWHs are recommended to be established close to a health facility where essential childbirth care and/or care for obstetric and newborn complications is provided to increase access to skilled are at birth for populations living in remote areas or with limited access to services" p.5.

In addition to commissioning a systematic review to determine the evidence of effectiveness of MWHs on key maternal health outcomes, the WHO also commissioned a background document to analyse the context and conditions and factors that affect implementation of MWHs. This article builds on that background document. The objective of this paper is to share with policy makers and implementers who are thinking about implementing MWHs key learnings from other implementation experiences, so that they can apply lessons to their own contexts.

\section{Methods}

This article is a secondary thematic analysis of studies identified in a systematic review of MWHs commissioned by WHO whose findings are summarized in the above-mentioned guidelines: [4] four existing systematic reviews [3, 18-20] and a systematic mapping of maternal health literature published from 2000 to 2012 were identified [21].

For this paper we included 29 studies identified through the above systematic reviews: 14 of these were included in the WHO-commissioned review and an additional 15 papers which were not included in the WHO-commissioned evidence review but included here as they described the implementation of MWHs, through qualitative or quantitative studies. The characteristics of the 29 studies included in this analysis are listed in Table 1.

We used the Supporting the Use of Research Evidence framework (SURE) framework [22] to identify different contextual and health system factors that affect implementation of MWHs and conducted data extraction on the key themes (See Table 2). The relevant information extracted on perspectives of women who used MWHs, community stakeholders, health care providers and other stakeholders; health service delivery factors; and social and political factors is presented in Table 3 and summarized below.

\section{Results}

Table 1 gives information on study design of the papers included. Fourteen of the papers included were impact studies, including 11 cohort studies, two cross-sectional studies and one review of records. The other fifteen papers were either qualitative or mixed method in research design. In two cases, no research design was reported. The dates of the studies ranged from 1978 to 2013, with the majority published between 2003 and 2013. Below we organize the analysis of implementation factors extracted from the different studies into five main categories.

Maternity waiting homes settings and target populations The included studies on MWHs were from countries in Africa (nine countries - Eritrea, Ethiopia, Ghana, Kenya, Liberia, Malawi, South Africa, Zambia, Zimbabwe), Latin America (four countries - Cuba, Guatemala, Honduras, 
Table 1 General characteristics of included studies

\begin{tabular}{|c|c|c|c|c|}
\hline$\overline{\text { Title }}$ & Study Design & Setting & Scale $^{2}$ & Description of Intervention \\
\hline $\begin{array}{l}\text { Ande-michael et al. } \\
\text { (2009) }\end{array}$ & $\begin{array}{l}\text { Hospital-based before and } \\
\text { after study with qualitative } \\
\text { component }\end{array}$ & $\begin{array}{l}\text { Eritrea, remote areas } \\
\text { of two coastal regions } \\
\text { of the Red sea }\end{array}$ & $\begin{array}{l}655,279 \text { people } \\
11 \mathrm{MWH}\end{array}$ & $\begin{array}{l}11 \text { health facilities with MWH for women } \\
\text { living at least } 10 \mathrm{~km} \text { distance from facility. } \\
\text { MWHs had an ambulance for referal to } \\
\text { higher level facilities for complications. } \\
\text { During admission, consumables were } \\
\text { provided to women. Community support } \\
\text { provided through supplies. Equity } \\
\text { considerations made for women residing } \\
\text { more than } 10 \mathrm{~km} \text { from health facility. Staff } \\
\text { at MWH were trained. Part of a strategy } \\
\text { implemented by } \mathrm{MOH}\end{array}$ \\
\hline
\end{tabular}

Chandra-mohan et al. Hospital cohort (childbirth (1994) outcomes over time)

Chandra-mohan et al. (1995)

Danel et al. (2003)

Ecker-mann et al. (2008)

Cohort analytic (two group pre + post)

World bank report

Case study with qualitative components

Feresu et al. (2003)

World bank report

Fraser (2008)

Case study

Garcia Prado et al. (2012)

Cross-sectional survey and qualitative components
Zimbabwe, Rural

Honduras, National

Lao People's

Democratic Republic (PDR), Remote-rural
208,000 people $1 \mathrm{MWH}$

208,000 people $1 \mathrm{MWH}$

Population $\mathrm{nr}$ $5 \mathrm{MWH}$

27,539 people No MWH, 17 to be built
Nicaragua, Rural

Zimbabwe National

Peru, Rural and urban $2 \mathrm{MWH}$ (390 available nationally)

Population $\mathrm{nr}$ $18 \mathrm{MWH}$
Gaym et al. (2012)

Hospital based cohort with a qualitative component
Overview of 255 $\mathrm{MWH}$

opulation $\mathrm{nr}$ implemented by $\mathrm{MOH}$

$150 \mathrm{~m}$ from lang stay at MWH from 36 weeks gestation. Target population was women identified as risk in ANC. MWH offered ANC and health education.

See Chandramohan et al., 1994

Attached to rural hospitals.

Improve maternal outcomes in remote communities with a high proportion of ethnic minorities and disadvantaged groups economically and in health indices. Women provided with nutrition and baby care training, handicraft training and have opportunity to earn an income while staying at $\mathrm{MWH}$. All given information and opportunities for micro-credit initiatives. MWHs designed for privacy before, during and after birth (for uncomplicated births conducted in MWH in traditional birthing position)

Reported outcomes of key interventions to address MMR in Peru. MWH near health centres that refer cases to hospitals. MWH are part of a strategy implemented by $\mathrm{MOH}$

Women spend 2 weeks before and 1 week after childbirth at $\mathrm{MWH}$, where food and lodging is provided. Most homes extend their services beyond medical visits and education on SHR, offering advice and counselling on diverse issues (domestic violence, selling handmade prouducts, and obtaining identify cards or land titles). Women referred from mobile health teams and TBAs. Situated near health centres. $\mathrm{MOH}$ has a strategy to promote MWHs.

Faith based organizations pioneered the construction of MWHs in Ethiopia since the late 1980's, then adopted by NGOs as well as public health facilities. Conditions within each varied, activities included outreach to increase community awareness of MWHs. Women referred by staff at peripheral health facilities, and outreach teams. Women also came based on recommendations from other women who had used facility. Situated within compound of health facility.

Gorry (2011) C Case study

Cuba, Rural and Population nr

15 MWHs were introduced in 1962 and grew to 327 . Existing houses are reconditioned to create a home-like environment for monitoring 
Table 1 General characteristics of included studies (Continued)

Kelly et al. (2010)

Hospital cohort (childbirth outcomes over time)

Ethiopia, Rural

$\begin{array}{ll}\text { Knowles et al. (1988) } & \text { Case study } \\ \text { Larsen et al. (1978) } & \begin{array}{l}\text { Hospital cross sectional } \\ \text { survey }\end{array} \\ \text { Lori et al. (2013a) } & \text { Qualitative study } \\ \text { Lori et al. (2013b) } & \begin{array}{l}\text { Cohort analytic (two group } \\ \text { pre }+ \text { post) }\end{array}\end{array}$

Martey et al. (1995)

Millard et al. (1991) Hospital cohort study

Mramba et al. (2010) Cross sectional survey, qualitative components Poovan et al. (1990) Hospital cross-sectional
survey

Ruiz et al. (2013)

Qualitative study

Schooley et al. (2009) Qualitative inquiry (focus groups and in-depth key informant interviews, unstructured, focused observations)

Shrestha et al. (2007) Cross-sectional survey and qualitative component

Spaans et al. (1998) Household-level cross-section

Tumwine et al. (1996) Cohort analytic (two group pre + post)

Hospital cross-section
Malawi

South Africa, Rural

Liberia, Rural, post conflict

Liberia, Rural post conflict

Ghana, Rural

Zimbabwe, Rural

Kenya

Ethiopia, Rural

Guatemala

Urban

Guatemala

Nepal, Lowland conflict

Zimbabwe

Zimbabwe

Zambia, Rural
60,000 people
800,000 people $1 \mathrm{MWH}$

health and wellbeing of woman and fetus. Concept has been further developed to emphasize nutrition and diet, and provision of ambulatory services so women can take meals and classes at $\mathrm{MWH}$, but return home in the evenings. MWHs follow guidelines designed by Ministry of Public Health's maternal child health program in collaboration with UNICEF, describing criteria for admission, diagnostic and clinical guidelines for identifying risk factors and protocols for treatment in MWHs.

40 bed MWH, located within hospital grounds. Original facility built in 1973 in local style with thatched roof, which caught fire in 1999; replaced by corrugated roof. A companion resides at $\mathrm{MWH}$, finds firewood and food, and cooks for her. High-risk women spend last few weeks of pregnancy in $\mathrm{MWH}$.

Population nr $1 \mathrm{MWH}$

Women referred from other medical facilities and can self-refer. Situated in hospital ground. $\mathrm{Nr}$

Served women affected by conflict. Women self-refer. Situated near health facilities.

Served women affected by conflict.

$>50,000$ people $4 \mathrm{MWH}$

131,229 people $5 \mathrm{MWH}$

$\mathrm{Nr}$

Population $\mathrm{nr}$ $1 \mathrm{MWH}$

Population nr $1 \mathrm{MWH}$

300,000 people $1 \mathrm{MWH}$

Population nr $2 \mathrm{MWH}$

Population $\mathrm{nr}$ $1 \mathrm{MWH}$

Population $\mathrm{nr}$ Study not linked to existing $\mathrm{MWH}(27$ $\mathrm{MWH}$ available)

Population nr $4 \mathrm{MWH}$

100,000 people Number of $\mathrm{MWH}$ $\mathrm{nr}$

Women self-referred themselves to the facility. 2 min walk from hospital. $\mathrm{MOH}$ policy exists supporting MWHs.

$50 \mathrm{~m}$ from the maternity unit at a District Hospital. It has a capacity of 40 people: 20 pregnant women and 20 healthcare workers. Referrals mostly by health workers. Referrals from health workers.

Women referred during outreach ANC conducted by nurse midwives and TBAs. Situated close to the hospital.

Focus on attracting indigenous women. Women referred from TBAs and health centre physicians. Women could also self-refer. $3 \mathrm{~km}$ from the hospital. Part of a $\mathrm{MOH}$ strategy to increase utilisation in this region.

Focus on increasing utilisation of health services by indigenous women. Situated adjacent to a local hospital.

Working in a context of conflict. $\mathrm{MOH}$ supported MWH to increase health facility utilisation.

In the hospital grounds.

Women referred by health centre staff, TBAs and could refer themselves. $100 \mathrm{~m}$ from hospital. 
Table 1 General characteristics of included studies (Continued)

\begin{tabular}{|c|c|c|c|c|}
\hline \multicolumn{3}{|c|}{$\begin{array}{l}\text { van Lonkhuij-zen et al. } \\
\text { (2003) }\end{array}$} & $1 \mathrm{MWH}$ & $\begin{array}{l}\text { Women referred during monthly outreach } \\
\text { clinics conducted by midwives. Situated } \\
\text { next to hospital. }\end{array}$ \\
\hline Wessel(1990) & Case study & Nicaragua, Rural & $\begin{array}{l}\text { Population nr } \\
1 \mathrm{MWH}\end{array}$ & $\begin{array}{l}\text { Aimed at supporting refugees from the } \\
\text { civil war. Self-referral. }\end{array}$ \\
\hline Wild et al. (2012) & Interrupted time series & $\begin{array}{l}\text { Timor-Leste } \\
\text { Remote-rural }\end{array}$ & $\begin{array}{l}>100,000 \text { people } \\
2 \mathrm{MWH}\end{array}$ & $\begin{array}{l}\text { Connected by a walkway to the hospital, } \\
\text { and near a health centre. } \mathrm{MOH} \text { run as } \\
\text { part of their maternal health strategy. }\end{array}$ \\
\hline Wilson et al. (1997) & $\begin{array}{l}\text { Qualitative study, with } \\
\text { MWH utilisation rates }\end{array}$ & Ghana, Rural & $\begin{array}{l}126,000 \text { people } \\
1 \mathrm{MWH}\end{array}$ & $\begin{array}{l}\text { Referrals from private midwives and } \\
\text { health posts. Situated in an unused } \\
\text { ward in the hospital. }\end{array}$ \\
\hline
\end{tabular}

1 Year of study or report; 2 Catchment population reportedly covered by $\mathrm{MWH}$ and number of MWH included in article; 3 Health indices reported as background levels in the article only, pertinent to locality, population of interest and time period where available. Health indices as a result of the MWH intervention not included

Abbreviations: $M M R=$ maternal mortality ratio/100000, $\mathrm{PMR}=$ perinatal mortality $/ 1000, \mathrm{SBA}=$ skilled birth attendance, IDR $=$ institutional delivery rate, $\mathrm{HB}=$ home births, $\mathrm{ANC}=$ antenatal care, $\mathrm{PHC}=$ primary health centres, $\mathrm{TBA}=$ traditional birth attendants, $\mathrm{MOH}=\mathrm{ministry}$ of health $\mathrm{nr}=\mathrm{not}$ reported

Nicaragua, Peru], and Asia (three countries - Lao PDR, Nepal and Timor-Leste).

Reported interventions were generally confined to a few districts involving one to five MWHs. However, articles from Cuba and Peru reported larger numbers of MWHs being built $[16,23]$. The majority of settings were rural. Some specifically targeted conflict areas, indigenous women, the socially excluded, or poor people. $[17,24,25]$ Depending on the location of the $\mathrm{MWH}$, women travelled from less than $5 \mathrm{~km}$ to $400 \mathrm{~km}$ to reach the closest MWH $[10,15]$. Along with large distances, several studies reported women having to cross difficult terrain to reach the facility. Most MWHs were situated next to a hospital facility, which provided essential childbirth care services and care for complications (comprehensive obstetric care services), although a few were placed near health centres that provided only essential childbirth care. Practices of referral to MWHs varied; women were referred by health professionals, from antenatal clinics or self-referred.

Table 2 Guide for extracting data and emergent themes

\begin{tabular}{|c|c|}
\hline Content of interest & Themes which emerged \\
\hline $\begin{array}{l}\text { - Demographic, socio-cultural, economic, country context } \\
\text { - Health indicators } \\
\text { - Health system characteristics } \\
\text { - Policy } \\
\text { - Community characteristics }\end{array}$ & \multirow[t]{3}{*}{ General characteristics of context and MWH } \\
\hline - Timeline & \\
\hline $\begin{array}{l}\text { - General equity considerations (e.g. gender, ethnic, racial, } \\
\text { marginalized and vulnerable populations) }\end{array}$ & \\
\hline $\begin{array}{l}\text { - Assumptions, theory of change, models or frameworks used } \\
\text { to guide program design and implementation }\end{array}$ & $\begin{array}{l}\text { Definition or description of } \mathrm{MWH} \text {, and hypothesis } \\
\text { or reasoning for establishment of } \mathrm{MWH}\end{array}$ \\
\hline $\begin{array}{l}\text { - Program context (key actors, organizations, participants, } \\
\text { implementing partners, \& who did what, who initiated the program) }\end{array}$ & \multirow[t]{4}{*}{ Administrative set-up and maintenance of $\mathrm{MWH}$} \\
\hline - Monitoring and evaluation system characteristics & \\
\hline $\begin{array}{l}\text { - Cost of intervention, financial considerations (e.g. incentives, } \\
\text { compensation), source of funding }\end{array}$ & \\
\hline $\begin{array}{l}\text { - Structural and financial support and considerations (organizational } \\
\text { systems, training/education and support for implementers/actors/ } \\
\text { participants) }\end{array}$ & \\
\hline \multirow[t]{2}{*}{ - Description of approach/intervention (process used) } & $\begin{array}{l}\text { Description of physical facilities, utilities provided and } \\
\text { infrastructure of MWH (e.g. bed size, number of rooms, } \\
\text { cooking, sanitation facilities) }\end{array}$ \\
\hline & $\begin{array}{l}\text { Health related activities at the MWH (e.g. health education, } \\
\text { training, antenatal care, income generation) }\end{array}$ \\
\hline - Inhibiting factors, challenges and enhancing factors & \multirow{2}{*}{$\begin{array}{l}\text { Barriers and enabling factors related to MWH based on } \\
\text { perceptions of (a) community (b) health workers (c) } \\
\text { authors of articles }\end{array}$} \\
\hline - Sustainability & \\
\hline
\end{tabular}


Table 3 Barriers and enablers to implementation of MWHs analysed using the SURE framework

\begin{tabular}{|c|c|c|c|c|}
\hline Level & Barriers & Article & Enablers & Article \\
\hline \multirow{2}{*}{$\begin{array}{l}\text { Main Stakeholders from } \\
\text { the Community-women } \\
\text { \& families }\end{array}$} & Knowledge and Skills & & & \\
\hline & Lack of knowledge of MWH & $\begin{array}{l}\text { - Mramba et al. } 2010 \\
\text { - Ruiz et al. } 2013 \\
\text { - Shrestha et al. } 2007\end{array}$ & $\begin{array}{l}\text { Awareness of MWHs and services } \\
\text { offered through community outreach } \\
\text { and mobilization is high among } \\
\text { women }\end{array}$ & $\begin{array}{l}\text { - Garcia Prado } \\
\text { et al. } 2012 \\
\text { - Gaym et al. } 2012 \\
\text { - Kelly et al. } \mathbf{2 0 1 0} \\
\text { - Poovan et al. } 1990 \\
\text { - Schooley et al. } 2009 \\
\text { - Wild et al. } 2012\end{array}$ \\
\hline
\end{tabular}

Women do not remember _ - Eckermann et al. 2008

the date of their last period, - Spaans et al. 1998

so unsure about expected

due date-point of entry into

$\mathrm{MWH}$ and duration of stay

uncertain and may be

prolonged

Attitudes regarding programme acceptability, appropriateness and credibility

Traditional childbirth

practices not

accommodated

- Eckermann et al.

2008

- Ruiz et al. 2013

Family members (husbands and mothers in law) don't allow women to use MWHs and no

- Mramba et al. 2010

one left at home to do

chores or provide child care - Ruiz et al. 2013

- Nhindiri et al. 1996
Integration of cultural norms and expectations into the care provided at the MWH and associated health facility

High awareness of benefits and acceptability of MWHs and facility birth among family and community members. Family and community actively involved through educational outreach and involved in decision-making.

High acceptability of facility births and use of MWHs among women
- Fraser 2008

- Lori et al. 2013b

- Ruiz et al. 2013

- Schooley et al. 2009

- Garcia Prado et al. 2012

- Gaym et al. 2012

- Kelly et al. 2010

- Lori et al. 2013 a

- Ruiz et al. 2013

- Schooley et al. 2009

- Wild et al. 2012

- Gaym et al. 2012

- Kelly et al. 2010

Health workers and users of MWH - Ruiz et al. 2013

have different ethnicities which

result in communication problems

Companion not allowed or unable - Eckermann et al. 2008

to accompany

- Gaym et al. 2012

- Ruiz et al. 2013

- Schooley et al. 2009

- Wild et al. 2012

Healthcare Providers Involved in

Implementing MWH

Other Stakeholders

\section{Knowledge and Skills}

Without access to technologies, not possible for health workers to predict date of delivery so duration of stay is uncertain and prolonged stay at MWH might occur

Attitudes regarding programme acceptability, appropriateness and credibility

Health workers and users of MWH have different ethnicities which result in communication problems

Knowledge and Skills
- Eckermann et al. 2008
Training TBAs and integrating TBAs into the birthing process helped encourage women to use MWHs and deliver in facilities

\section{- Andemichael \\ et al. 2009}

- Lori et al. 2013a

- Lori et al. 2013b

- Poovan et al. 1990

- Schooley et al. 2009 
Table 3 Barriers and enablers to implementation of MWHs analysed using the SURE framework (Continued)

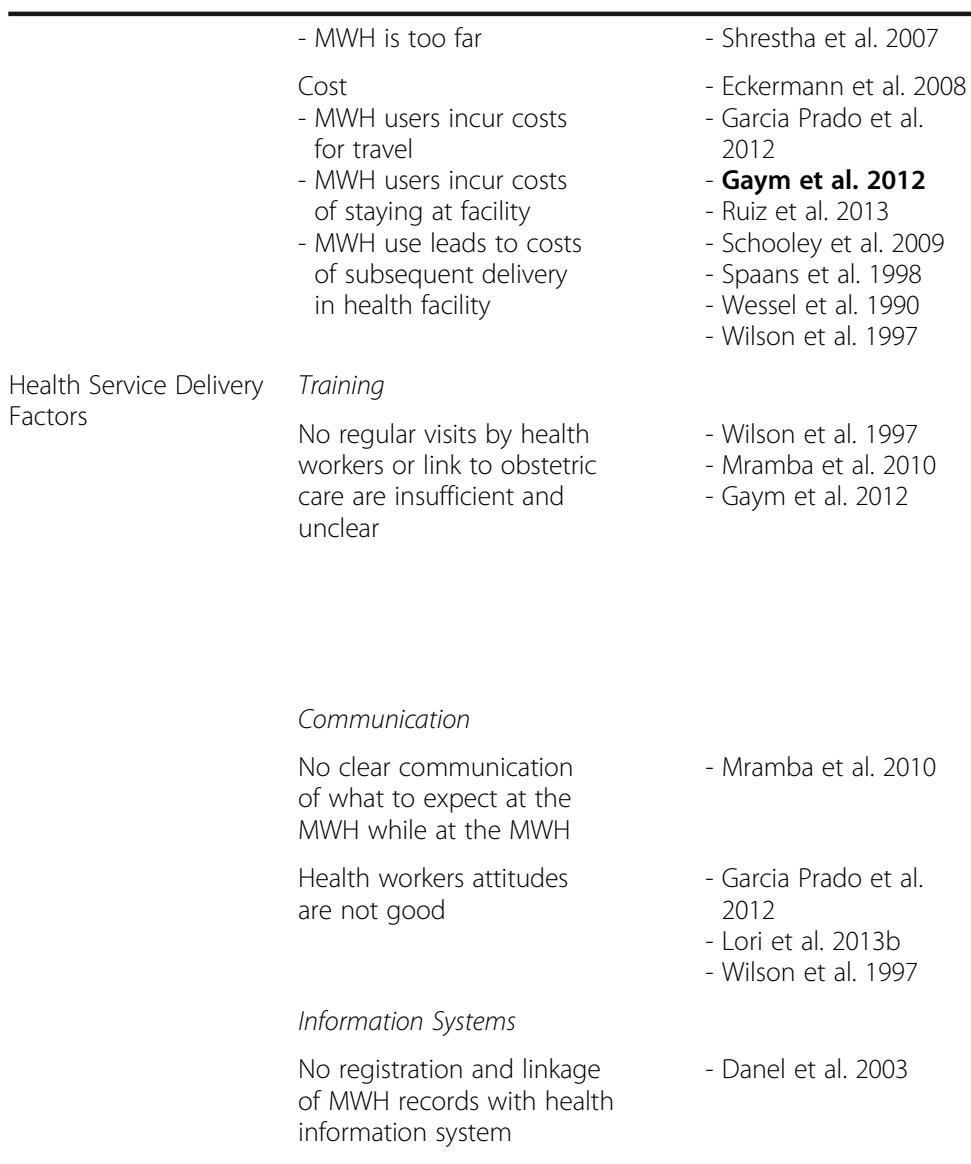

Strong referral and communication systems between $\mathrm{MWH}$ and associated facilities, including transportation and communication equipment facilities to provide good quality of care
- Kelly et al. 2010

- Ruiz et al. 2013

- Spaans et al. 1998

- Wessel 1990 tensive training of health providers in $\mathrm{MWH}$ and

Daily visits to the MWH by midwives

Poovan et al. 1990

- Fraser 2008

- Gorry 2011

\section{Chandramohan \\ et al. 1995}

- Gaym et al. 2012

- van Lonkhuij-zen

et al. 2003

- Lori et al. 2013a

- Mramba et al. 2010

Eckmann et al. 2008 MWH provides and maintains all

- Kelly et al. 2010

- Lori et al. 2013b

- Mramba et al. 2010

- Nhindiri et al. 1996

- Ruiz et al. 2013-

Schooley et al. 2009

- Shrestha et al. 2007

- Wild et al. 2012

- Wilson et al. 1997 needed facilities, including basic infrastructure such as electricity, kitchen/food facilities, and bathing and toilets. MWH also provided a space for companions and family members to stay with the pregnant woman.

- Ruiz et al. 2013

- Food not provided leading for MWH users. Women had to travel back to their homes to replenish supplies

- A lack of space for postpartum women

Useful activities to occupy women's time and provide knowledge and skills are not organised or insufficient (for example: entertainment, income generation skills, health education)

- Eckermann et al. 2008

- Ruiz et al. 2013

- Mramba et al. 2012

- Lori et al. 2013b
Activities to occupy women's time, including education and income generation activities, helped improve acceptability and use of MWH among women
- Gorry 2011

- Ruiz et al. 2013

- Tumwine et al.

1996

- Wessel 1990

Intervention integrity 
Table 3 Barriers and enablers to implementation of MWHs analysed using the SURE framework (Continued)

\begin{tabular}{|c|c|c|c|c|}
\hline & & & $\begin{array}{l}\text { of care, in both the MWH and health } \\
\text { facilities associated with the MWH }\end{array}$ & $\begin{array}{l}\text { - Tumwine et al. } \\
1996\end{array}$ \\
\hline \multirow{5}{*}{$\begin{array}{l}\text { Social and Political } \\
\text { Factors }\end{array}$} & Legislation or regulations & & & \\
\hline & & & $\begin{array}{l}\text { Enabling policy environment, which } \\
\text { included inclusion of supportive MWH } \\
\text { policies in national and/or local } \\
\text { legislation }\end{array}$ & $\begin{array}{l}\text { - Fraser } 2008 \\
\text { - Gorry } 2011 \\
\text { - Lori et al. } 2013 b \\
\text { - Millard et al. } 1991\end{array}$ \\
\hline & Sustainability & & & \\
\hline & $\begin{array}{l}\text { Lack of community } \\
\text { involvement in } \mathrm{MWH} \\
\text { set up, support and } \\
\text { maintenance }\end{array}$ & $\begin{array}{l}\text { - Poovan et al. } 1990 \\
\text { - Kelly et al. } 2010 \\
\text { - Lori et al. } 2013 \text { a } \\
\text { - Ruiz et al. } 2013 \\
\text { - Shrestha et al. } 2007 \\
\text { - Wilson et al. } 1997\end{array}$ & $\begin{array}{l}\text { Involve community members and } \\
\text { family in the design, development, } \\
\text { and maintenance of the MWH }\end{array}$ & $\begin{array}{l}\text { - Lori et al. 2013b } \\
\text { - Poovan et al. } 1990 \\
\text { - Schooley et al. } 2009\end{array}$ \\
\hline & & - & $\begin{array}{l}\text { MWH and facilities are able to adapt to } \\
\text { changing health needs of women. For } \\
\text { example, in Cuba, an economic crisis } \\
\text { meant needing to focus and integrate } \\
\text { nutrition improvement for pregnant } \\
\text { women in the MWH }\end{array}$ & - Gorry 2011 \\
\hline
\end{tabular}

Articles that are highlighted in bold are those that were included in the systematic review of effectiveness of $\mathrm{MWHs}$

\section{Administrative set up and maintenance of maternity waiting homes}

There is diversity in the stakeholders who took responsibility to establish the MWHs in the different studies included. The programmes in Cuba and Peru were large scale and, at least initially, adequately funded and supported by their respective National Ministries of Health. These MWHs were implemented as part of a national programme to improve maternal health outcomes, alongside new protocols, staff training, and improved referral and support for women [16, 23]. Aside from these examples, little information was found on policy support for MWHs at a national level.

The remainder of the MWHs consisted of isolated projects, supported by non-governmental and donor organisations. A number of articles reported community support and contribution to the setup and ongoing running of the MWH. The need for the community to be involved in the set up and maintenance of the $\mathrm{MWH}$ was identified in three studies, and six studies identified the absence of community involvement as a reason for low utilization of the MWH programme [13, 17, 26-29].

Several studies reported on MWH residents incurring user fees for antenatal care or childbirth services $[10,17,25,29-33]$. The removal or reduction of costs associated with using the MWH and subsequent institutional birth were noted as important strategies for increasing MHW use. In two studies, financial incentives were even offered for women, who were charged less for childbirth services if they stayed in the MWH $[13,17]$. The provision of free food by the MWH varied across settings. In Cuba, meals were provided and tailored to the nutritional needs of each woman in consultation with dieticians at the MWH [16], while in other MWHs, food or kitchen facilities were available for the women to arrange their own meals [10, 16, 18, 31, 33]. However, in instances where women and their families were required to provide their own meals, inequalities in terms of volume and quality of food emerged among the women [10, 13, 33, 34].

A number of studies reported that simply building a $\mathrm{MWH}$ did not overcome barriers to accessing care as women still needed financial resources to get to the MWH $[15,17,25,28,30]$. The cost of public transportation to reach the MWH was a common barrier to its use and varied depending on the mode of transport distance and time of day [13]. Considerable costs were also reported for securing private transport. The comfort and speed of the transport, as well as the terrain covered were other elements considered by women [13, 30]. In Laos PDR, women were refunded transport costs. In Nicaragua and Laos PDR, women and their families indicated that upfront support for transportation costs would be important $[23,30]$.

\section{Physical infrastructure and facilities provided}

A range of building types were used for MWHs, including unused wards of hospitals [29], traditional huts [12] and purpose-built structures. Some buildings had several separate rooms, each with a few beds [27], while others had large dormitories [17]. Total bed space ranged from 4 to to 83 [31]. In planning for the construction of a MWH in South Africa, Larsen et al. estimated that the size of a MWH should be based on 500 women per 1000 births in a district, with each stay averaging two weeks [35]. 
Living and social spaces, as well as utilities like electricity or water, kitchens, cooking utensils, toilets and bathrooms, lockers, bedding and firewood, were described in some papers. From the perspectives of women who used the facility, a lack of privacy, poor toilet and bathing facilities, poor or inadequate kitchen facilities, the non provision of food, and lack of space for women to stay post-partum were considerable barriers to MHW use. $[10,13,15,17,25,27-30,36$, 37] Overall, MWHs were better used and accepted by women and their families when they provided basic infrastructure and facilities such as those mentioned above [17, 27, 36, 37]. In one MWH in Ethiopia the availability of a hot shower was very popular with women [13].

In some situations, accommodation was provided for relatives, including mother in laws $[17,28]$. Women cited companions not being allowed - either at the MWH or in the facility - as an additional factor undermining acceptability of MWHs [10, 15, 17, 25, 30]. Finally, in interviews with women and families, acceptability of MWH was noted as being higher if activities were available for women to do while awaiting childbirth, such as health education and income generation activities [14, 16, 17, 33].

\section{Health services and linkages with the facility}

Various criteria were used to accept women into MWHs, from identified obstetric risk factors for complications, to open admission. Women were advised to stay for between one to four weeks before childbirth and, in some MWHs, for up to seven days after birth. Two studies suggested that sometimes uncertainty around a woman's due date meant that she did not know when it was appropriate to come to the MWH [30, 32]. MWHs were sometimes also used as places for women to stay before and after undergoing postpartum tubal ligation at the hospital or other health facilities [10, 33, 38].

Studies suggest that strong referral and communication systems between the MWH and the facilities they are linked to are important, as well as a focus on providing high quality care in both the $\mathrm{MWH}$ and the facility linked to the MWH $[14,16,17,25,26,32,34,37,39,40]$. The type and quality of maternity care services received by women varied. Three studies noted that there were no regular visits by health care providers to the MWH and that referral from the MWH to the facility was not smooth [10, 29, 36]. In other sites, women regularly attended the nearby health facility, or were visited in the MWH by staff from the facility $[14,26,31]$. Standard guidelines for care processes, including criteria for admissions, diagnostic and clinical guidelines for identifying risk factors, and protocols for treatment in MWH settings, were reported in Cuba [16].
Community involvement and sensitivity to cultural norms Linking with traditional birth attendants (TBAs) was seen as enabling the success of MWH programmes. Five studies identified this as critical to facilitating access to MWHs, specifically, through the training of TBAs and the integration of them into the preparation for birth and birthing process both at the MWH and at the facility [24-27, 39].

In four studies, the integration of cultural norms around birthing and improved awareness that the MWH provided respectful and humanized care were key to getting women and their families to use both MWH and the nearby facility for birth [17, 23-25]. Finally, on the issue of cultural norms, concerns were expressed by women in Guatemala around health workers belonging to a different cultural group to those attending $\mathrm{MWH}$, and the potential for this to pose linguistic challenges and also to undermine respect for a woman's cultural beliefs [17, 31].

A number of studies identified outreach to the community, often using existing community health structures, as key to the success of a MWH project [25-28].

Community involvement was important to identify cultural factors that affected the use of the MHW; for example, family members, namely the husband or mother-in-law, would not "allow" women to use the MWH or to be away from the household for an extended length of time due to childcare and other household duties [17, 27, 31, 36, 37]. Awareness building efforts were especially important in places where community members had little knowledge of the MWH, which in itself constituted an important barrier to MWH use [17, 28, 36].

Overall, activities to increase community awareness of the MWH services were considered a vital facilitator of MWH uptake $[10,13,15,25,26,31]$. MWHs were embraced in those communities where family members and the larger community had been made aware of the importance of facility births $[10,13,15,17,24,25,28,31]$.

\section{Discussion}

\section{Limitations and research gaps}

We identified several limitations in this review. The wide variations in the organization, functioning and operationalization of MWHs, and how women were screened for $\mathrm{MWH}$ residence means that the studies are difficult to compare.

Most papers did not specifically set out to either document the contextual factors or assess barriers and facilitators. A number of factors that may play a key role on the implementation of these programmes were not reported (see Table 1). Surprisingly, there was relatively little in the reviewed literature around health care workers attitudes towards MWHs and how these 
affected implementation. Issues such as community participation were stressed as important in many articles, but what was meant by community participation and how community participation was ensured was not expanded upon. Studies that did seek community input often obtained information from women who were already users of facilities, rather than non-users. Nonetheless the included studies provide rich findings.

The studies included were generally of small-scale projects, although examples of scaled-up MWHs were available from Peru and Cuba. We have only drawn from published literature, but we are aware that there may be other experiences of implementation of $\mathrm{MWH}$ programmes from which lessons could be drawn, as many programmes may not be implemented as part of research or with a research component. This is particularly true of programmes implemented by National Ministries of Health.

Publication bias cannot be ruled out although the collection of systematic reviews and extensive search strategy for the Mascot mapping aimed to minimise this [21].

When considering implementing MWHs, key factors to be addressed include: 1) Community engagement, ensuring input is obtained from women and other community members as to the design and running of the MWH, identification of barriers to the use of MWH's that need to be addressed and recommendations about how the community can be involved in maintaining the quality of the MWH's; 2) the quality of the MWH structure, including cleanliness, living conditions, and the safety of women staying there; 3) the quality of maternity care services provided at the corresponding health facility; and 4) the financial and operational sustainability of the MWH.. The literature suggests that there is not one model that fits the diversity of contexts but it is clear there are multiple issues that require discussion with key stakeholders in order to address the factors that will affect implementation and ensure integration in to the health system.

Maternity Waiting Homes are not isolated interventions and one of the key challenges to its successful implementation is how well it can be embedded within the health system and integrated within community patterns, preferences, behaviours and other related services. Some interventions have presumed the following: women find birth in a health facility acceptable; the financial and indirect costs of residing away from home are affordable; and women's basic rights to comfort, companionship, tradition, information and quality of care are respected. However the studies in this review have shown that these elements are variable and heavily dependent on the local context. We also see that there are multiple factors that affect care seeking for childbirth services; distance is only one factor. The MWH needs to be imbedded in a programme that addresses the other factors including costs, household decision making, knowledge of services, women and community perceptions of quality of care, etc.

The community perspectives in the studies reviewed demonstrate there is general awareness of the benefits offered by $\mathrm{MWH}$, particularly when the community is consulted and involved. Involvement can range from participation in a governing committee, to faith-based organizations spearheading the physical construction of $\mathrm{MWH}$, to community volunteers supporting individuals or running programmes within the facility.

The literature also suggests that it is important that all those involved in promoting maternal and newborn health and providing maternity care services must know about MWHs. It is likely that provision of MWH should be included in community health workers training, birth and complication preparedness, voucher programmes and other efforts to improve the levels of birth with a skilled attendant in rural and remote areas.

The 'readiness' of the linked health facility is also crucial. The literature suggests that women will not use $\mathrm{MWH}$ even when they are available if they are not confident about the care they will receive in the linked health facility. The quality of care (both respectful and medical quality) provided in the health facility should be adequate to improve both acceptability and health outcomes of childbirth.

\section{Conclusion}

At policy level, there may be utility in development of guidelines and protocols on the physical infrastructure, utilities and services provided at the $\mathrm{MWH}$, and community consultation. Additionally, clear identification of capital costs is required, along with a functioning management structure, regular flow of resources for maintenance and a defined relationship with the linked health facility and the health system.

Improved and harmonized documentation of implementation experiences would provide a better understanding of the factors that impact on successful implementation. As is illustrated in Table 1 many of the articles did not record key information that would have been useful to enable implementation lessons to be learnt.

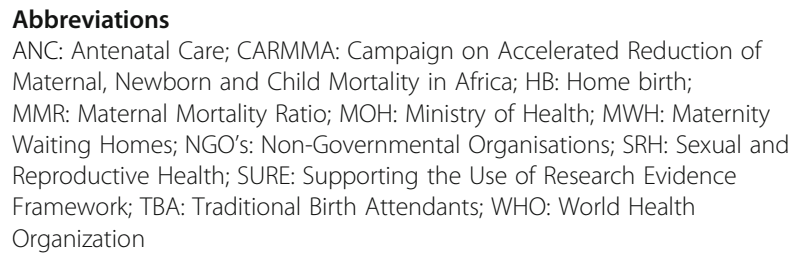

\section{Acknowledgements}

All the reviewers who reviewed articles for the systematic mapping of maternal health literature published from 2000 to 2012. 


\section{Funding}

The first stage of this review was completed as part of two research projects: the Multilateral Association for Studying Health Inequalities and Enhancing North-South and South-South Cooperation Project (MASCOT), which received funding from the European Union's Seventh Framework Programme FP7/ 2007-2013 under grant agreement number 282507, and the Maternal Health in South Africa and Rwanda (MHSAR) project, funded by the Netherlands Organisation for Scientific Research. The second stage of the review was commissioned by the Department of Maternal, Newborn, Child and Adolescent Health of the World Health Organization with funding support from the Norwegian Agency for Development Cooperation.

\section{Availability of data and materials}

All information quoted in the article is available in published articles that are referenced at the end of the article.

\section{Authors' contributions}

This paper is based on an original analysis conducted by JH and SM, commissioned by WHO. JH and SM conducted the review, extracted data, interpreted the findings and developed a first draft of the manuscript. LPK and SP carried out analysis of the data using the SURE framework. HB helped with analysis and development of the Tables. AP gave substantial comments at all stages of the process, and rewrote sections of drafts and the final manuscript. MC lead the systematic review from which this work was extracted, and made substantial contributions to the way that the data was analysed and written. He made significant inputs on all drafts. All authors contributed to the writing of the manuscript and reviewed drafts of the manuscript before submission. All authors have read and approved the final version of this manuscript.

\section{Ethics approval and consent to participate}

Ethical approval for this project was not needed, as it was a review of published material.

\section{Consent for publication}

Not applicable

\section{Competing interests}

The authors declare no conflict of interest. Anayda Portela is a staff member of the World Health Organization and is responsible for the views expressed in this article which do not necessarily represent the decisions, policy or views of the World Health Organization.

\section{Publisher's Note}

Springer Nature remains neutral with regard to jurisdictional claims in published maps and institutional affiliations.

\section{Author details}

'School of Public Health, Faculty of Health Sciences, Centre for Health Policy/ MRC Health Policy Research Group, Private Bag X3, University of the Witwatersrand, Johannesburg 2050, Gauteng, South Africa. ${ }^{2}$ Department of Infectious Disease Epidemiology, London School Hygiene and Tropical Medicine, Keppel Street, London WC1E 7HT, UK. ${ }^{3}$ Department of Global Health and Development, London School Hygiene and Tropical Medicine, 15-17 Tavistock Place, London WC1H 9SH, UK. ${ }^{4}$ Immpact, Institute of Applied Health Sciences, University of Aberdeen, Foresterhill, Aberdeen AB25 2ZD, Scotland. ${ }^{5}$ Department of Maternal, Newborn, Child, Adolescent Health, World Health Organization, 20, Avenue Appia, 1211 Geneva, Switzerland. ${ }^{6}$ Wits Reproductive Health and HIV Institute, Faculty of Health Sciences, University of the Witwatersrand, Johannesburg, South Africa. ${ }^{7}$ Department of Obstetrics and Gynaecology, College of Health Sciences, University of Zimbabwe, Mazowe Street, Harare, Zimbabwe.

Received: 28 April 2016 Accepted: 4 August 2017

Published online: 31 August 2017

\section{References}

1. Campbell OM, Graham WJ. Strategies for reducing maternal mortality: getting on with what works. Lancet. 2006;368:1284-99.
2. WHO UNFPA UNICEF World Bank. Reduction of Maternal Mortality: A Joint WHO/UNFPA/UNICEF/World Bank Statement. Geneva: World Health Organisation; 1999.

3. Holmes W, Kennedy E. Reaching emergency obstetric care: overcoming the 'second delay'. Burnett Institute: Melbourne, Australia; 2010.

4. Organisation WH. WHO Recommendations on Health Promotion Interventions for Maternal and Newborn Health. Geneva: WHO; 2015.

5. World Health Organisation. Maternity Waiting Homes: A review of experiences. Geneva: World Health Organisation, Maternal and Newborn Health Safe Motherhood Unit. Division of Reproductive Health; 1996.

6. United Nations Population Fund. No Woman Should Die Giving Life 2015 27th October 2015. Available from: http://carmma.org/update/carmmahigh-level-event-african-leaders-unite-"prioritise-women-and-childhealth".

7. Kruk ME, Galea S, Grepin KA. External Evaluation of Saving Mothers, Giving Life. New York: Columbia University; 2013.

8. University of North Carolina. UNC to improve safe motherhood effort in Malawi2015 27th October 2015 Available from: http://news.unchealthcare. org/som-vital-signs/2013/july-18/with-an-8-million-grant-from-the-bill-andmelinda-gates-foundation-unc-will-improve-safe-motherhood-in-malawi.

9. Latin American Center for Perinatology Women and Reproductive Health. Plan of action to accelerate the reduction of maternal mortality and severe maternal morbidity: monitoring and evaluation strategy. Montevideo: 2012.

10. Gaym A, Pearson L, Soe KW. Maternity waiting homes in Ethiopia-three decades experience. Ethiop Med J. 2012;50(3):209-19.

11. Chandramohan D, Cutts F, Chandra R. Effects of a maternity waiting home on adverse maternal outcomes and the validity of antenatal risk screening. Int J Gynaecol Obstet. 1994;46(3):279-84.

12. Millard P, Bailey J, Hanson J. Antenatal village stay and pregnancy outcome in rural Zimbabwe. Cent Afr J Med. 1991;37(1):1-4.

13. Kelly J, Kohls E, Poovan $\mathrm{P}$, Schiffer $\mathrm{R}$, Redito A, Winter $\mathrm{H}$, et al. The role of a maternity waiting area (MWA) in reducing maternal mortality and stillbirths in high-risk women in rural Ethiopia. BJOG. 2010;117(11):1377-83.

14. Tumwine JK, Dungare PS. Maternity waiting shelters and pregnancy outcome: experience from a rural area in Zimbabwe. Ann Trop Paediatr. 1996;16(1):55-9.

15. Wild K, Barclay L, Kelly P, Martins N. The tyranny of distance: maternity waiting homes and access to birthing facilities in rural Timor-Leste. Bull World Health Organ. 2012;90(2):97-103

16. Gorry C. Cuban maternity homes: a model to address at-risk pregnancy. MEDICC Rev. 2011;13(3):12-5.

17. Ruiz MJ, van Dijk MG, Berdichevsky K, Munquia A, Burks C, Garcia SG. Barriers to the use of maternity waiting homes in indigenous regions of Guatemala: a study of users' and community members' perceptions. Cult Health Sex. 2013;15(2):205-18.

18. van Lonkhuijzen L, Stekelenburg J, van Roosmalen J. Maternity waiting facilities for improving maternal and neonatal outcome in low-resource countries. Cochrane Database Syst Rev. 2012;10:CD006759.

19. Hussein J, Kanguru L, Astin M, Munjanja S. The effectiveness of emergency obstetric referral interventions in developing country settings: a systematic review. PLoS Med. 2012;9(7):e1001264.

20. Lee AC, Lawn JE, Cousens S, Kumar V, Osrin D, Bhutta ZA, et al. Linking families and facilities for care at birth: what works to avert intrapartumrelated deaths? Int J Gynaecol Obstet. 2009;107(Suppl 1):S65-85-S6-8.

21. Chersich MBD, Dumbaugh M, Penn-Kekana L, Thwala S, Bijlmakers L, Vargas E, Kern E, Kavanagh J, Dhana A, Becerra-Posada F, Mlotshwa L, BecerrilMontekio V, Mannava P, Luchters S, Pham MD, Portela AG, Rees H. Mapping of research on maternal health interventions in low- and middle-income countries: a review of 2292 publications between 2000 and 2012. Global Health. 2016;Sep 6;12(1):52

22. Evidence-Informed Policy Network. SURE Guides for Preparing \& Using Evidence-Based Policy Briefs GENEVA: WHO; 2011 [27th October 2015]. Available from: http://www.who.int/evidence/sure/guides/en/.

23. Fraser B. Peru makes progress on maternal health. Lancet. 2008;371(9620): 1233-4.

24. Lori JR, Wadsworth AC, Munro ML, Rominski S. Promoting access: the use of maternity waiting homes to achieve safe motherhood. Midwifery. 2013; 29(10):1095-102.

25. Schooley J, Mundt C, Wagner P, Fullerton J, O'Donnell M. Factors influencing health care-seeking behaviours among Mayan women in Guatemala. Midwifery. 2009;25(4):411-21.

26. Poovan $\mathrm{P}$, Kifle $\mathrm{F}$, Kwast BE. A maternity waiting home reduces obstetric catastrophes. World Health Forum. 1990;11:440-5. 
27. Lori JR, Munro ML, Rominski S, Williams G, Dahn BT, Boyd CJ, et al. Maternity waiting homes and traditional midwives in rural Liberia. Int J Gynaecol Obstet. 2013;123(2):114-8.

28. SD S. Feasibility study on establishing Maternity Waiting Homes in remote areas of Nepal. Regional Health Forum 2007;11(2):33-38.

29. Wilson JB, Collison AH, Richardson D, Kwofie G, Senah KA, Tinkorang EK. The maternity waiting home concept: the Nsawam, Ghana experience. The Accra PMM Team. Int J Gynaecol Obstet. 1997;59(Suppl 2):S165-72.

30. Eckermann E, Deodato G. Maternity waiting homes in Southern Lao PDR: the unique 'silk home'. J Obstet Gynaecol Res. 2008;34(5):767-75.

31. Garcia Prado A, Cortez R. Maternity waiting homes and institutional birth in Nicaragua: policy options and strategic implications. Int J Health Plann Manag. 2012;27(2):150-66.

32. Spaans WA, van Roosmalen J, van Wiechen CM. A maternity waiting home experience in Zimbabwe. Int J Gynaecol Obstet. 1998;61(2):179-80.

33. Wessel L. Casa Materna brings care to rural women in northern Nicaragua. Maternal mortality and morbidity: a call to women for action. Amsterdam: Women's Global Network for Reproductive Rights; 1990.

34. Chandramohan D, Cutts F, Millard P. The effect of stay in a maternity waiting home on perinatal mortality in rural Zimbabwe. J Trop Med Hyg. 1995;98(4):261-7.

35. Larsen J, Muller E. Obstetric care in a rural population. S Afr Med J. 1978; 54(27):1137-40.

36. Mramba L, Nassir FA, Ondieki C, Kimanga D. Reasons for low utilization of a maternity waiting home in rural Kenya. Int J Gynaecol Obstet. 2010;108(2):152-3.

37. Pea N. A community-based study on utilisation of maternity services in rural Zimbabwe. African Journal of Health Services. 1996;3(4):120-5.

38. Danelwith IR, A, . Honduras, 1990-1997 In: Koblinsky M, editor. Reducing Maternal Mortality: learning from Bolivia, China, Egypt, Honduras, Indonesia, Jamaica and Zimbabwe. Health, nutrition, and population series. Washington, DC: The World Bank; 1993.

39. Andemichael GH, Haile B, Kosia A, Mufunda J. Journal of Eritrean Medical Association. In: Maternity Waiting Homes: A panacea for maternal/neonatal conundrums in Eritrea; 2008.

40. Feresu SN, M Mumbwanda, L Zimbabwe, 1980-2000. In: Koblinsky M, editor. Reducing Maternal Mortality: learning from Bolivia, China, Egypt, Honduras, Indonesia, Jamaica and Zimbabwe. Health, nutrition, and population series. Washington DC: The World Bank; 2003.

\section{Submit your next manuscript to BioMed Central and we will help you at every step:}

- We accept pre-submission inquiries

- Our selector tool helps you to find the most relevant journal

- We provide round the clock customer support

- Convenient online submission

- Thorough peer review

- Inclusion in PubMed and all major indexing services

- Maximum visibility for your research

Submit your manuscript at www.biomedcentral.com/submit 